\title{
6th Pacific Rim Conference on Rheology
}

\author{
20-25 July 2014, The University of Melbourne, Australia
}

This issue of the Korea-Australia Rheology Journal includes a series of papers based on work presented at the $6^{\text {th }}$ Pacific Rim Conference on Rheology, organised by the Australian Society of Rheology, and held successfully in Melbourne from $20^{\text {th }}$ to $25^{\text {th }}$ July 2014. The Pacific Rim series of rheology conferences was first held in Kyoto, Japan in 1994, followed by Melbourne, Australia in 1997, Vancouver, Canada in 2001, Shanghai, China in 2005, and then in Sapporo, Japan in 2010. The latest conference constitutes the $20^{\text {th }}$ year anniversary of the first event. The conference attracted over 200 delegates from 20 countries, with nearly two thirds from outside of Australia, implying a diversity of involvement from outside the Pacific Rim.

The scientific sessions of the workshop covered the following topics: (a) Self-assembling Systems (Associative Polymers, Surfactant Solutions and Liquid crystals), (b) Gels, Glasses and Granular Materials, (c) Polymeric Fluids, (d) Colloids, Suspensions and Emulsions, (e) Food and Biological Rheology, (f) Interfacial and Microrheology, (g) Rheometry and Experimental Techniques, and (h) Non-Newtonian Fluid Mechanics. Papers in each of the sessions were grouped into the following three themes: (i) Industry and Environment, (ii) Theory versus Experiment, and (iii) Modeling and Simulations.

There were five excellent plenary speakers (Yuichi Masubuchi, Susan Muller, Debra Bernhardt, Gareth McKinley, Myung Hwan Kim), and a large range of keynote speakers. Professor Tam Sridhar was honoured with a special one-day symposium within the technical program. Ten internationally renowned rheologists (Raj Chhabra, Rakesh Gupta, David James, Ron Larson, Gary Leal, Giuseppe Marrucci, Gareth McKinley, Susan Muller, Robert Prud'homme, Eric Shaqfeh), who have all collaborated and been closely associated with Tam Sridhar, presented talks at the symposium.

The conference gratefully acknowledges the significant cash and in-kind contributions from the University of Melbourne and Monash University, and many other sponsors and exhibitors, for helping to make the conference possible and in particular, giving graduate and younger rheologists in Australia and the Pacific Rim the opportunity to listen to and interact with such eminent scientists.
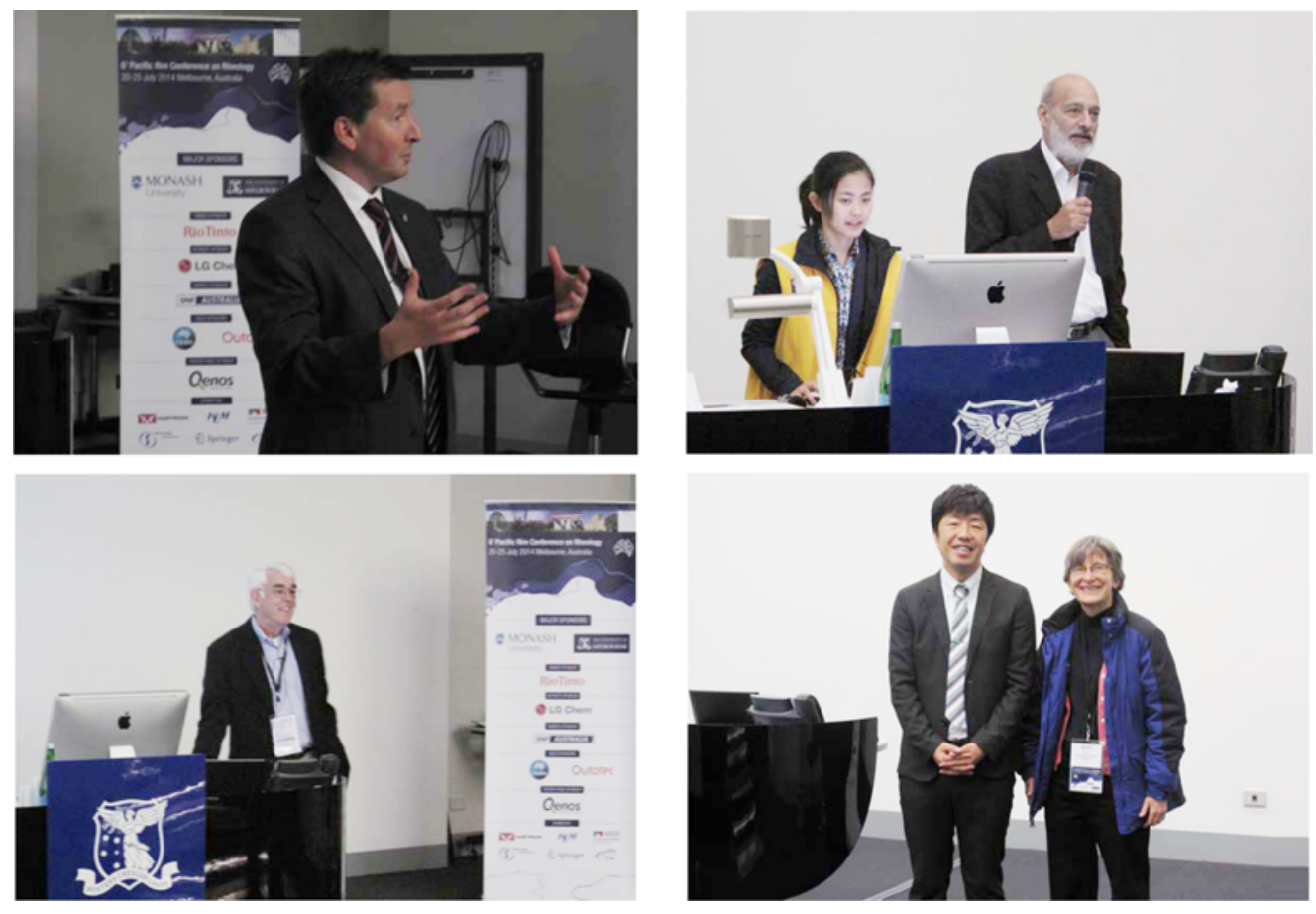

Corresponding author; E-mail: ravi.jagadeeshan@monash.edu (Prof. Ravi Prakash Jagadeeshan) 